\title{
"The Magical Device": \\ Temple Grandin's Hug Machine
}

Novina Göhlsdorf

In August of 1947, when Temple Grandin was born in Boston, her mother perceived her as "a normal, healthy newborn" and a "quiet, 'good' baby girl" (Grandin/Scariano 1996: 23). According to Grandin, the mother felt a change after her daughter was six months old: "I was no longer cuddly and ... stiffened up when she held me. When I was a few months older, Mother tried to gather me into her arms, and I clawed at her like a trapped animal" (ibid.). Grandin describes the resistance to her mother's hugs as the first indication of her "disorder" (ibid.: 9). The impossibility of hugging her is also one of the starting points of Grandin's narrative of her life, which is depicted as thoroughly shaped by autism. In her account, her reactions and relations to embraces appear as a nucleus for most of her personal evolution. They are, often painfully, intricate. For she longed to be hugged but could not bear the tactile stimulation, because she was physically overwhelmed by it. As a teenager, she invented a machine that gave her much-needed hugs of a sort she could endure and eventually enjoy. She continually transformed the device and made it her mundane companion: her hug machine.

Grandin's hug machine - a leitmotif in her story - is the topic of this article. I will first show how its emergence was strongly interlaced with her development as she reports it - her own versatile emergence, which too is the title of her autobiography. Secondly, I will examine the machine's materiality, and the functions and effects 
Grandin attributes to it. Largely, she delineates it as a tool for handling challenges associated with her autism, mitigating her sensory difficulties, structuring her mental world, and teaching her to connect to others. However, her representations of the apparatus do not fully account for its instrumental features that supposedly make her function better, despite her condition. Thus, thirdly, I will explore the device as an actant in its own rights. Here, Grandin and the machine will not be analyzed as a bounded and one-sided constellation of a subject in charge and an object in use, but rather as an open and dynamic assemblage formed by two acting and interacting parties. Instead of depleting symptomatic expressions of a supposed "disorder," this association of a human and a machine generates experiences and affects beyond the categories of psychiatric pathology and treatment. Based on this perspective, I will, fourthly, address the question of how the synergies between Grandin and her machine might entail a sociality and relationality that is genuinely more than human. Finally, in view of recent statements by people with autism, I will contemplate this sociality and relationality as a potential autistic way of being in touch.

\section{The Emergence of Temple Grandin}

At the age of two, Grandin became a medical case. She compiles a list of features she did or, mostly, did not exhibit at that time: "no speech, poor eye contact, tantrums, appearance of deafness, no interest in people, and constant staring off into space" (2006: 33). As it turned out that she was not deaf, a neurologist deemed her "brain-damaged" (ibid.). A couple of years later, she was "labeled autistic" (Grandin/Scariano 1996: II). In her writings, Grandin retrospectively corroborates this label by picturing herself as a child showing typical signs of so-called "classic autism," like the traits and non-traits registered above. Contemporarily however, in the late 1940s and around 1950, autism as a distinct nosologic category was still in its earliest infancy, too. It was not yet a simply given and widely known diagnostic denomination, nor did there exist any subdivision like "classic." Against recommendations to put her in an institution, Grandin's mother created an individualized educational program for her at home. Grandin eventually began to speak and went to kindergarten, school, and college. She finished a Ph.D. and is today a renowned animal scientist and an internationally acknowledged designer of livestock systems (cf. Jacobson 2012). 
In 1986, the by then 39-year-old Grandin published the earliest broadly received autobiography by an author with autism. ${ }^{2}$ Emergence is a memoir of her life up to this point. It is a success story. The book in itself figures as the very manifestation of Grandin's achievements: the ultimate "emergence" of someone who was characterized by an inability to express herself intelligibly and was expected to forever remain immersed in her own private universe.

Moreover, every page of the text underpins Grandin's role as the first public expert on autism with autism. ${ }^{3}$ As a specialist on her own case, she shapes and proclaims a particular idea of autism. In opposition to a long-prevailing concept of it being a psychogenic disorder, a child's response to the psychic trauma of cold parenting, ${ }^{4}$ she defines autism as a developmental condition that derives from neurological irregularities bringing forth a "defect in the systems which process incoming sensory information" (Grandin/Scariano I996: 9). This defect "causes the child to over-react to some stimuli and under-react to others" (ibid.). For Grandin, all presumably generic symptoms of autism, including the notoriously invoked closed "world of one's own" (cf. Göhlsdorf 20I9a), are effectuated by misguided and therefore overwhelming or imperceptible input from the senses: "The autistic child often withdraws from her environment and the people in it to block out an onslaught of incoming stimulation" (Grandin/Scariano I996: 9).

"The autistic child" Temple Grandin once was herself is portrayed as either oblivious to external stimulation or, above all, as highly vulnerable to it, especially to touch. Touch regularly provoked "nerve attacks" (ibid.: 75) in her. In the book, hugs recur like floods of stimuli. Hugs from a large relative caused anxiety in Grandin: "I was totally engulfed and I panicked. It was like being suffocated by a mountain of marshmallows. I withdrew because her abundant affection overwhelmed my nervous system" (ibid.: 29-30). Due to what Grandin speaks of as her autism-related "tactile defensiveness" (ibid.: 36, I36), she was not able to shake someone's hand until into her twenties. ${ }^{5}$ She wanted to be touched, yearned for a specific combination of physical warmth and pressure. However, she could not stand the perceptual overload. "It was a conflict situation. In order to get over the tactile defensiveness, I needed tactile stimulation but I withdrew" (ibid.: 38). She tried to find relief by wrapping her body in blankets or weighting herself down with pillows. 
Still a young girl, she started to fantasize about an apparatus providing the right type of stimulation - in other words, a machine that gave her the hugs she wished for, "available at any time to soothe" (ibid.: 36) her and under her own control (ibid.: 58). This "magical device" (ibid.: 90), to cite Grandin, is metaphorically and literally at the center of her book. ${ }^{6}$ What at first was a secret reverie (ibid.: IOo) eventually became her most important project.

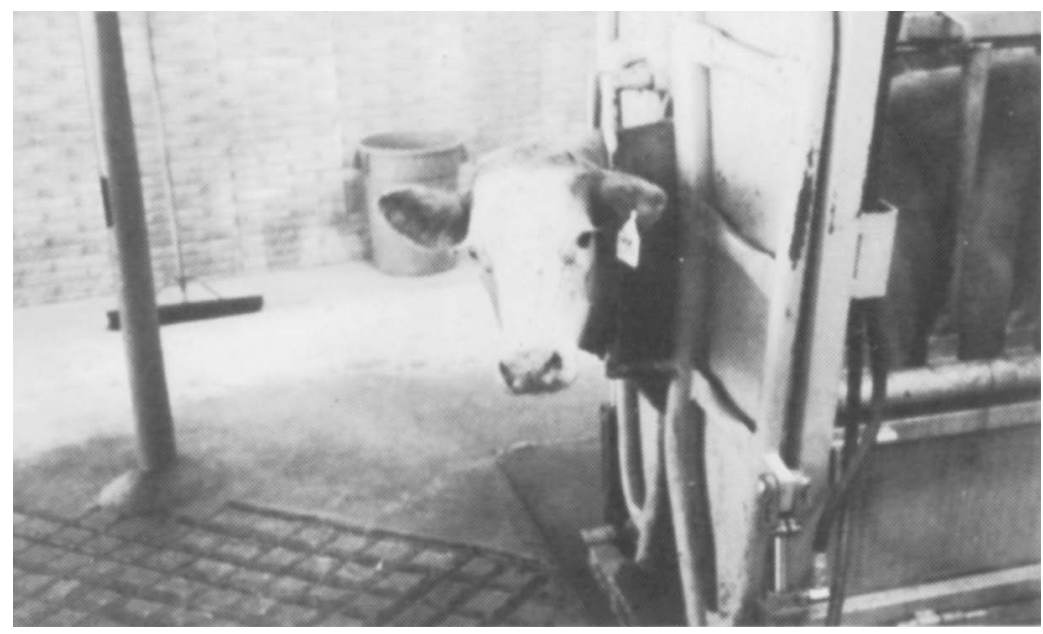

At the age of fifteen, she visited her aunt's farm where she discovered the "squeeze chute," a steel and wood device used for calming down cows before they were branded or vaccinated. The animal was driven into the chute, its head positioned into a gate. By pulling a rope, the side panels were closed and pressed against the flanks of the cow. Grandin noticed how this appeased the nervous animals. She had her aunt operate the cattle chute with herself, Grandin, inside, to find out if it had the same palliating effect on her, who was regularly suffering from anxiety and the aforementioned "nerve attacks." It did mollify her (cf. 1996: 93-95). She pictures her first moment in the cattle chute as a turning point in her life. Her childhood dream seemed viable: a magical device giving her hugs on demand, and of a kind she could tolerate. 


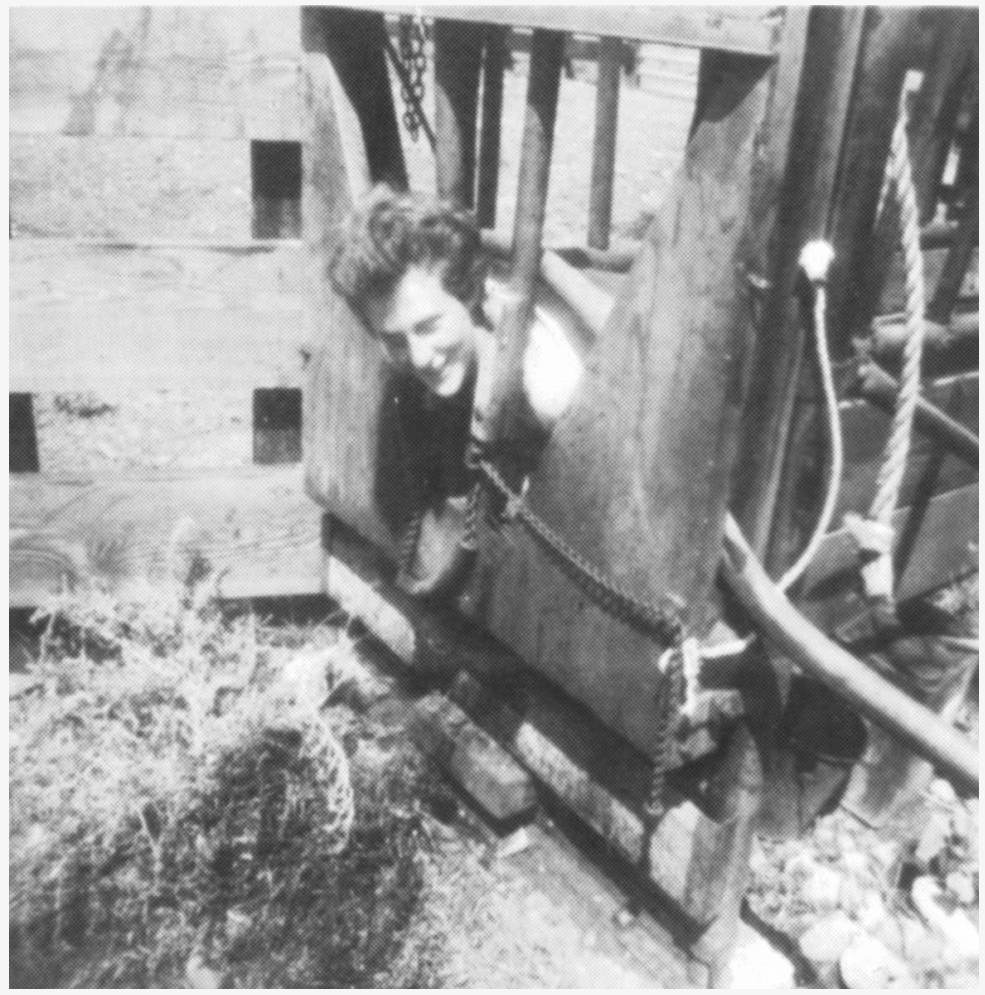

Fig. 2: Grandin in cattle chute

(Grandin/Scariano 1996: 95), (c) Arena Press 
The cattle chute became a model for what Grandin alternately calls her squeeze chute, squeeze machine, or hug machine. A teacher helped her construct a wooden apparatus replicating the chute on her aunt's farm. The teacher and her aunt were the only ones who approved of Grandin's machine (ibid.: 99). Psychiatric experts around her interpreted it psychoanalytically, attributing it to perverse sexual fantasies, for example (ibid.: I08). More importantly, her mother, presented as her main guardian, supporter and confidante throughout the book, was also against it. The strong opposition to the apparatus provoked feelings of guilt and inner conflicts in Grandin (ibid.).

When in college, she started to scientifically rebut the symbolic charge of the squeeze machine and verify its effectiveness, aiming to legitimize her usage of it. She investigated the contemporaneous research on sensory interaction and built a foam-padded prototype - PACES (Pressure Apparatus Controlled Environment Sensory) - a "Cadillac" (ibid.) compared to the first version. She asked test subjects to enter it and collected empirical data, showing that sixty-two per cent of the "normal [i.e., non-autistic] college students" (ibid.: IIO) appreciated being held by the machine and reported relaxation. Gradually, Grandin's affinity for the apparatus was accepted by those close to her. She also implies that these experiments were the beginning of her career as a scientist, with squeezing machines, sensory input, and livestock being recurring topics in her work (cf., e.g., ibid.: 130). She studied animal sciences, wrote her master's thesis on the design of cattle chutes, and later developed methods for slaughtering cattle. Today she ranks as a pioneer in the area of animal handling.

Grandin's narrative of herself builds on the machine. It is a dominant protagonist in her autobiography, staged as the pivotal condition of all of her accomplishments. It continued to be a significant motif in her writing. Be it in texts on autism, visual thinking, cattle behavior, or her empathy toward animals, the object - the squeeze machine - is frequently a prominent subject (cf. Grandin 2006; Grandin/Johnson 2006, 2010).

\section{The Hug Machine As an Instrument and Tool}

The setup of the hug machine was inspired by agricultural and industrial engineering. Determined by her respective resources and needs, Grandin adapted its construction and design over time. In spite of the various changes, the general, purely mechanical functionalities stayed the same, and no advanced or digital technology 
was ever involved in the machine's configuration. The prototype modeled after the cattle chute on Grandin's aunt's farm was a simple device made of rough scrap wood. Like the chute, the earliest variant had to be operated by another person. Grandin soon modified it and was able to "lock" and "release" (Grandin/Scariano I996: I0o) herself independently.

Two side boards are hinged at the bottom to form a V-shape. The user enters it and is embedded in it, lying down prone in the V-shaped space, lifted up from the floor. By moving a hand gear, the boards close in around her. Similar to the chute for farm animals, the first versions of the machine merely transmitted pressure, yielding a tranquilizing result due to the sheer compression. The later prototypes became more and more comfortable and they exerted less force, since Grandin's desire for "very intense pressure, almost to the point of pain" (Grandin 2006: 60) had decreased. Padding the side boards with foam rubber and fake fur added softness and a more complex quality to the squeeze. She also equipped the machine with a head rest and an upholstered element to sustain the neck (Grandin/Scariano 1996: I2O; Grandin 2006: 60). Thus, her body was supported from head to toe and fully embraced.

Although the basic arrangement - the V-shaped boards encircling a user in a horizontal position - was maintained throughout the prototypes, Grandin enhanced the pushing mechanism, for instance with a lever-operated pneumatic valve, aiming to apply a deep touch along both flanks of the body. Moreover, this had the result that the pressure was even and could be most subtly amplified and attenuated (Grandin/Scariano I996: I30-I3I). ${ }^{7}$

The hug machine affects Grandin on at least three levels: physical, mental, and interpersonal. It is sometimes difficult, in fact, to distinguish those levels in her text, and many of her statements suggest that their very distinction impedes a proper understanding of the apparatus's work. It is nevertheless of heuristic value to differentiate them at first. The primary effect Grandin describes is a bodily one, initiating all other impacts. The apparatus emits sensory stimuli and, depending on the prototype, the touch is harder or gentler. Besides stimulating her, the device fastens her. The touch and the fixation calm her down, but only given that the pressure is 

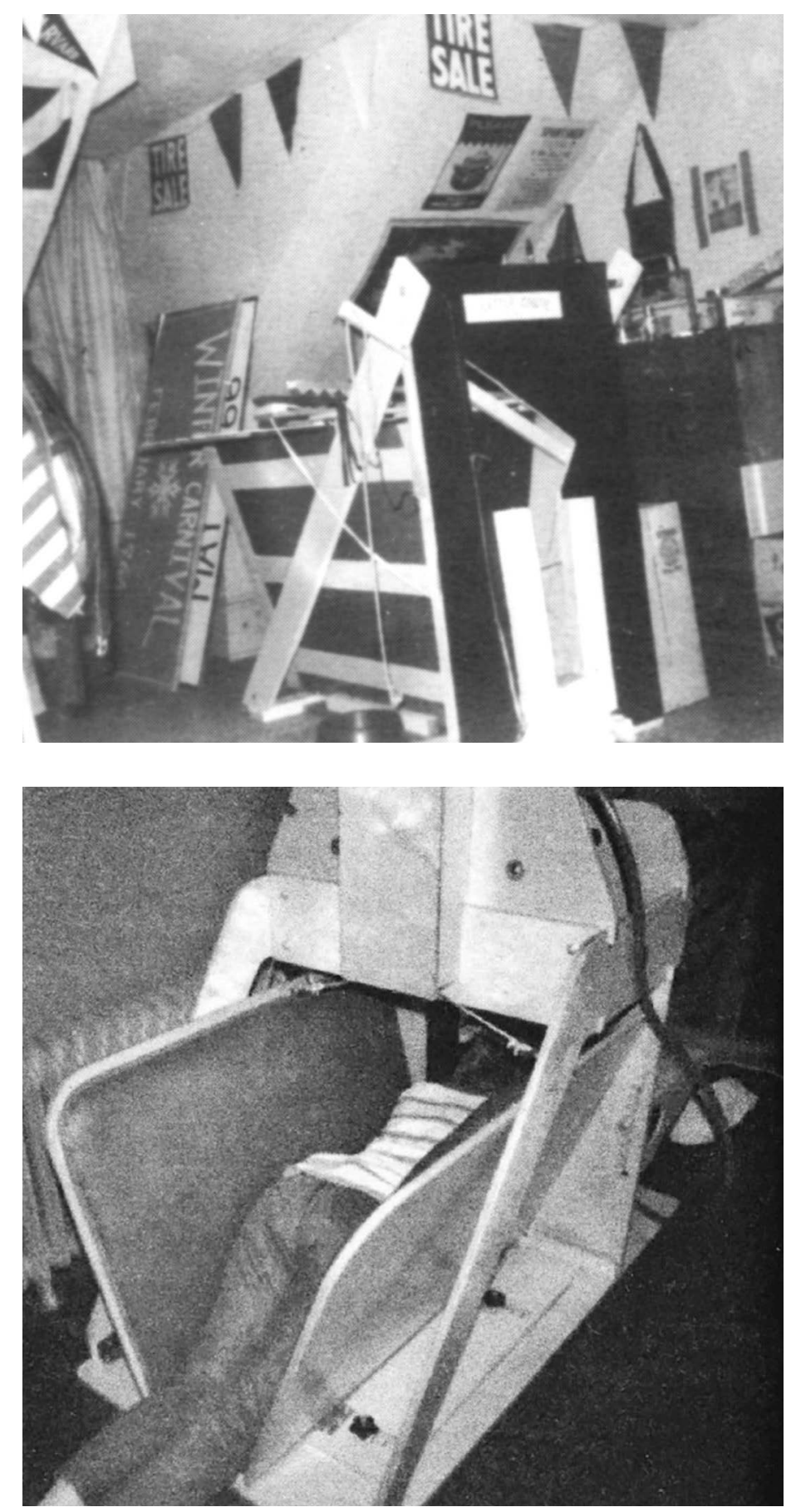
firm enough to surpass a particular threshold. Within this threshold, the touch is intolerable due to its lightness and makes her react with adamant resistance. Even when a sufficiently high pressure is achieved, she still needs to come to terms with "being confined" (ibid.: IIo).

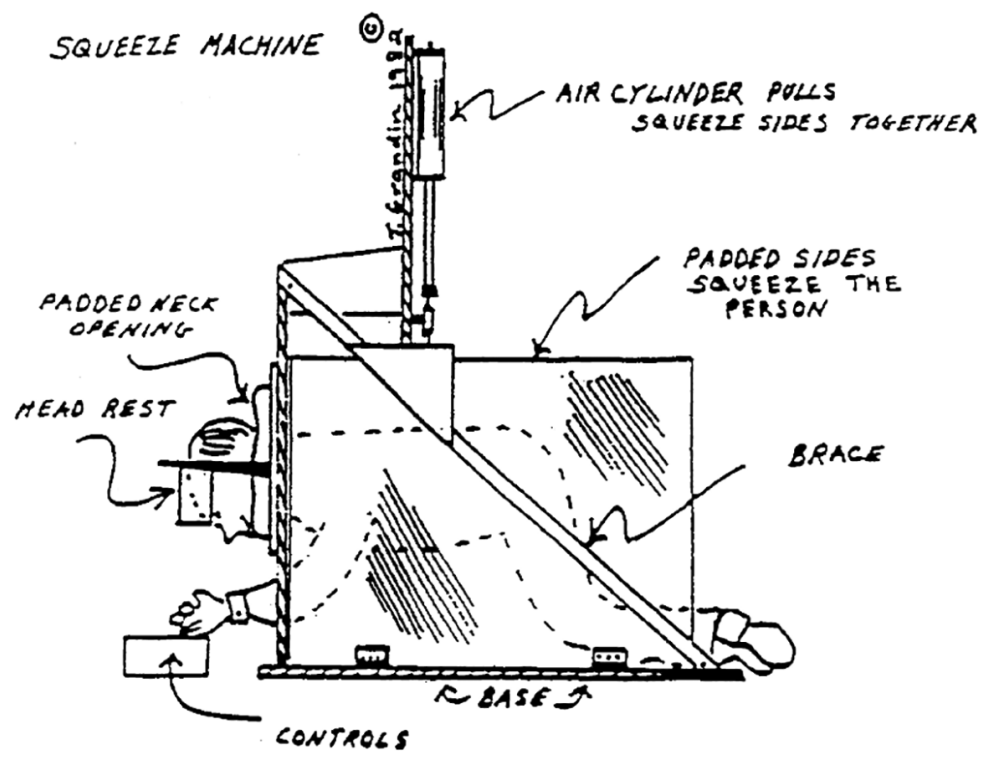


At the moment she first entered the cattle chute at her aunt's farm, she already realized that relief took effect solely after successfully restricting herself and overcoming the urge to withdraw:

I had to walk in calmly and quietly and not scream and struggle when the lever that would close a metal yoke around my neck was pushed down ... I had a panicky urge to jump out before the steel bars entrapped me. But I controlled myself and did not bang against the sides. (Ibid.: IO2)

She had to yield to the touch she would usually escape from, had it been elicited directly by humans. Only then she felt pleasantly stimulated and relaxed at the same time. After frequently applying the machine to herself as a disciplinary force, Grandin became increasingly capable of defeating the compulsion to fight the constraint (ibid.: IIO, I2O).

She utilized it as a training tool for self-control, which, in this case, is just as much a loss of control, or even more: a controlled loss of control, since she was the one steering the movement of the side boards. This, in turn, helped her gradually reduce her "tactile defensiveness": "I was finally beginning to be able to endure brief physical contacts like a pat on the shoulder or a handshake“ (ibid.: I09). She grants the machine healing, or rather, repairing faculties, as it supposedly fixes the "damaged nervous system" (ibid.: III) she traces back to autism. According to her, the apparatus can "cause new neural circuits to form" (ibid.) that she holds to be missing or broken in autistic people's brains. The less Grandin felt overpowered by the machine, the more she could deploy it as a source of comfort and regalement. Thus, she employed it as a motivating reward: "[S]ince I wouldn't allow myself the relaxation/stimulation of the chute until my homework was completed, the squeeze chute served as an incentive" (ibid.: IOo).

In Grandin's account, her corporal perceptions provoked by the device are accompanied by specific mental processes. Like the ability to manage her bodily reactions to tactile stimuli, her capacity to handle outbursts grew, for example: "I learned to control my aggression" (ibid.: I2O). She also faced affective and emotional ${ }^{8}$ states of new or unknown sorts, again due to a dialectic of forced submission and opened-up sensation. "I was learning how to feel," (ibid.: I08) she writes. "It was as if an accordion folding door had been shoved back revealing my emotions" (ibid.: IOo). This confrontation was an initially distressing one for her. In qualifying the machine as a device that taught her "to feel," she hints at a genuine deficiency within herself, implicitly 
confirming psychological assumptions about autism she otherwise condemns (ibid.: 57). ${ }^{9}$ The apparatus offered an ambience in which she could mentally experience what had before been imperceptible to her. In it, she was able to "accept affection" (ibid.: 120) and practiced grasping inner motions or representing them (ibid.: IOo).

The hug machine is a powerful medium of affects and emotions, inducing or amplifying them, raising her awareness of them and rendering their reflection possible. Here, Grandin trained herself in processing not only perceptual information but affective or emotional input and output as well. Her depictions ascribe psychotherapeutic functions to the apparatus. It unfolds an inward space and allows for its non-judgmental introspection. It might even recall a traditional psychoanalytic setup - a reversed couch - fostering what correspondingly would be framed as regression. Of course, instead of a talking cure, it facilitates a tactile one, and in place of stirring transferences between patient and therapist, it guarantees complete seclusion from human interaction, enabling very distinct transferences. In any case, however, it inspires Grandin to establish a connection with a self that simultaneously is developing in this very process. The machine is thus a technology that enhances technologies of the self, ${ }^{\text {o }}$ generating, shaping, and regulating a subject in its relation to itself.

Interestingly, Grandin refers to "feelings" or "affection" mainly as manifestations of interpersonal bonds. She had "thoughts about love" (ibid.) while in the machine. Only there could she truly realize that others cared about her or vice versa. "[I]t provided a warm, soft, comfortable environment which helped me receive and give affection" (ibid.: 133). Experiencing, differentiating and acknowledging her own mental states made her more aware of those of other people. It afforded her feelings for related parties (ibid.: I2I). She indicates that, within an enclosed setting ensuring retreat, solitude, and physical distance from others, she sensed attachment to them that had not been accessible to her before. Some passages suggest that her readiness to be emotionally touched coincides with and is indistinguishable from her capacity to permit her body to be held (ibid.: IOO). Grandin mentions contemporary theories of autism that associate it with a supposed deficit in empathy (ibid.). Drawing on primate research and her own biography, she wonders if this results from an absence of hugs in early life:

Feeling the soothing pressure from the squeeze machine slowly enabled me to start to have feelings of empathy. I wrote in my diary: 'Children have to be taught to be gentle. Since I missed out on this, I have to learn it now. The squeeze chute gives the feeling of being held, cuddled and gently cradled in Mother's arms ...' 
... I speculate that the regular use of the squeeze machine may help change some of the abnormal biochemistry which was caused by the lack of comforting tactile stimulation during my early childhood. Maybe the lack of empathy in many autistic adults is caused by their avoidance of hugging and affection when they were children. (Ibid.: I09) ${ }^{\mathrm{II}}$

Grandin conceives of the hug-providing and affection-triggering machine as an empathy training device that helps her catch up on lessons she could not learn as a child (ibid.: I08-I09). She credits it with altering her relationships to others and reducing what is to date delineated as a key symptom of autism spectrum disorders: "social communication impairments" (American Psychiatric Association 2013): "I was making great strides in communicating with people. I attributed this "breakthrough' in getting along better with people to my ... squeeze machine" (Grandin/ Scariano 1996: 108).

Encompassing the physical, mental, and interpersonal level, the squeeze machine constitutes a testing scenario and learning environment for Grandin. She often praises it as a potent self-help instrument that aids with challenges she believes to be caused by autism. Thus, it evokes three conflicting therapeutic contexts: firstly, much like many psychoanalytic or psychodynamic methods, it prompts emotive processes and their observation. Secondly, it changes perceptions and conduct similar to behavioral techniques exerting physical stimuli. And thirdly, it addresses neuro-cognitive, i.e. biological, systems by means of sensory input. Altogether, it instigates self-modification (ibid.: IOo). In Grandin's view, it helped normalize and integrate her into a neurotypically determined society (Almanza 20I6: I63), into "the world of love and human understanding" (Grandin/Scariano 1996: 36).

However, by focusing on these therapeutic functions and effects of the object, one might overlook how it opens up other worlds overall. For, more implicitly, Grandin also points to a differently productive and not merely instrumental dimension of the apparatus. From this perspective, one does not perceive her as a subject using it primarily as a tool that fulfills training or remedial purposes. Rather, one sees the whole setting - the mechanized hug between Grandin and her "magical device" as an assemblage generating states that do not solely compensate or alleviate deficits. What if we disregarded it as a device facilitating the entrance into spheres that are populated by humans who are - ideally - self-aware, properly delimited, and suffused with identifiable emotions? What if we examined it, instead, as an actant in its own right? And what is it, then, to be hugged by a machine? 


\section{Assembling Grandin and the Hug Machine}

Often, Grandin presents the apparatus as an object substituting for humans by granting her embraces she was not otherwise able to receive. It hence appears as a proxy or makeshift, its inanimateness a defect that has to be accepted. But when one considers all aspects of the machine mentioned by Grandin, one has to also ascribe a peculiar and innate quality to its very nonhumanness, an important surplus deriving precisely from it being a lifeless entity. This status can neither be apprehended as mere limitation nor as an intermediate step on the road to "true" interpersonal encounters. It constitutes an important feature in itself.

In separating it from other people, the hug machine makes physical contact always available. Its mechanics allow for the exact determination of the degree of pressure one exposes oneself to, and due to its construction, the touch is particularly intense, intimate, and extensive. It envelops almost all parts of the body, giving an all-embracing hug that no fellow human could offer. Whereas another person could only provide local and small-scale touches, the machine completely surrounds Grandin. Regardless of the theories and research results that she uses to explain its impacts, the device emerged from physical experiences, from trying out a chute designed for cattle and recognizing its sensory effects. Its development initially proceeded without any discourse but rather through bodily practices and the way they affected her. It primarily creates experiences that subvert any framework of social communication. They are determined neither by mutual expectations nor by the exchange of meanings or symbols. They account for communication only in the most genuine sense: as commerce, an exchange of forces, of hugs that consist in pure sensation with specific properties, depending, for example, on its firmness or temperature.

In spite of the inner struggle it provoked in the first moments, once Grandin was capable of opening herself to the stimulation, it relaxed her and gave her pleasure. This was her main impetus to build the squeeze chute and to hold on to it, despite the widespread disapproval and her own immediate resistance to its stimuli. Apart from deploying the machine as a means to diminish the symptoms of her condition, she also and increasingly resorted to it for sensual relief and indulgence: for self-stimulation. Self-stimulation has long been pathologized ${ }^{12}$ and made a target of intervention within the psy disciplines. Lately, however, it has been acknowledged as a valuable "self-regulatory mechanism" (Kapp et al. 20I9: I), notably for people 
exhibiting sensory processing difficulties. Within autism communities, it is being more often referred to as "stimming" and endorsed as an engine that is equally relieving, joyful, and empowering. For autistic literary scholar Melanie Yergeau, it "is desirous and self-exploratory and self-fulfilling" (2018: 202). In the course of her analyses, Yergeau emphasizes that "stims harbor ... possibility - the possibility of self-soothing, or self-regulating, or releasing" (ibid.: 204). Thus, the machine can itself be regarded as self-technology, but only by giving a new meaning to the word here. As opposed to shaping a self that can more smoothly fit into a fabric composed of interacting people, it enables one to meet one's needs and wishes self-sufficiently, without conceding one's aloneness. Self-sufficiency and aloneness have been held to be key manifestations of autism since its earliest description as a discrete syndrome, ${ }^{\mathrm{I} 3}$ and its treatment was typically aimed at attenuating them. In lieu thereof, the squeeze machine complies with an urge for reclusiveness.

Grandin's ambivalence toward the apparatus also derived from her own reservations about turning to a bare object with her desire for embraces and attributing such power to it. This was all the more so since this object was patterned on a chute often crudely applied to animals (cf. Grandin/Scariano I996: I22-I23, I26). Then again, the very interplay with the machine circumvents the categorical discriminations that her concerns are based on, since it suspends any clear distinction or constellation of subject and object. The subject position remains in abeyance here - is it Grandin steering the apparatus, or the apparatus affecting her? Certainly, it makes her equally potent and vulnerable. ${ }^{14}$ This becomes most obvious considering Grandin's already discussed controlled loss of control while in the machine. In one passage, she brings up a crucial detail about the points of transition between mastery and impotence, addressing an effectively ungovernable factor: As soon as the pressure gets too overwhelming for her, she can unlock herself, but before the release motion sets in, she has to tolerate a moment of being immobilized, without any room for maneuver (Grandin 2006: 76). In this short but critical instant, the squeeze machine can be recognized most clearly as a party that acts.

Even when it operates less autonomously, though, the machine is an actant - in the sense this term was given by philosopher and sociologist Bruno Latour, who distinguishes nonhuman "actants" from human "actors" (I999: I80). ${ }^{15}$ Latour promotes a new notion of "the social" based on the omnipresent collectives or "associations of humans and nonhumans" (2004: 83). He advocates abolishing a conception of the social founded firstly on a dichotomy of subjects and objects, and secondly on agency belonging exclusively to subjects supposedly pursuing intentions (ibid.: 246). 
Instead, he explicates acting in an inclusive sense, not taking it for "a property of humans but of an association of actants" (Latour 1999: I82, original emphasis). ${ }^{16}$ In his understanding, acting is not defined by purpose but is solely tied to changes in the other involved party, hence always already taking place within collectives (Latour 2004: 75). Acting things are thus more than ancillary objects: "In addition to 'determining' and serving as a 'backdrop for human action'," they "might authorize, allow, afford, encourage, permit, suggest, influence, block, render possible, forbid, and so on" (Latour 2005: 72). Building on this, he outlines a social composed of versatile and intermittent networks that emerge from the reciprocal interactions between diverse parties (ibid.: 65), resulting in "variable ontologies" (Latour I993: 85).

The conjunction of Grandin and her hug machine can be interpreted as a human-nonhuman association in the way Latour delineates it, in particular due to his underlying idea of an actor or actant: "any thing that does modify a state of affairs by making a difference" (Latour 2005: 7I). Seen in this light, Grandin and her machine both act, because they modify each other. By "habits ... rather than essences" (Latour 2004: 86, original emphasis), they constantly engender bilateral variations. These transformations occur during every single use of the machine.

Despite its angular and non-organic design, the hug machine offers an environment that corresponds to an inverted human body, fitted to fully contain Grandin. Thus, it invites being engaged with in a specific manner. When she enters the machine, its elements support her whole figure and sustain her entire weight, provoking at once a change of her position, perspective, and self-perception. Its leverage encourages a certain form of being manipulated, in Latour's words, a "programme of action" (2000: I8), enabling certain activities, disabling others. So already by accessing the machine, proposals and forces between the two participants are being "swapped." ${ }^{17}$ Subsequent to prompting the clasp of the side boards, the device squeezes Grandin's body, influencing her physiological and mental condition and thereby the state in which she then continues to direct the mechanism. After this initial movement, at the latest, Grandin's position as the first yet "unmoved mover" becomes volatile. Especially due to the possibility to induce, at least temporarily, her own passivity, agency here is intricately divided between human and machine. Both contribute to diverse "[c]irculations, sequences, transfers, translations, displacements, crystallisations" (ibid.: IO). The association or assemblage of Grandin and her machine renders these phenomena mentioned by Latour as concrete as possible, since both of their kinetic energies are continuously being shifted. The configuration is driven by ongoing transmissions and processes of mutual affordance and allowance. 
Grandin and the machine alter each other in the long term as well. As shown before, the use of the apparatus changes her on multiple levels. Also proceeding from her development in this way, she reconstructs, adjusts, and supplements its mechanics, breeding further complexities and subtleties in its mode of operation. She and the device are each increasingly stabilized as actor and actant, respectively, with more multifaceted dispositions and alternatives to perform. Not only are Grandin's options for feeling and behaving expanded with the help of the machine, and not only does she eventually obtain the status of a "high-profile figure" (Murray 2008: 32); the device, too, becomes progressively nuanced and ultimately less individualized and idiosyncratic. First modeled after an appliance for cattle and strongly resembling it, it took shape as the handiwork of an amateur and a unique specimen for Grandin's own personal use, which was repeatedly rebuilt. Finally, it served as a prototype for an industrially manufactured and commercially distributed item advertised for people with autism. ${ }^{18}$ This might imply that it finally turned into a mere therapeutic tool. Presumably, however, any person's association with a hug machine generates synergies that do not simply reduce impairments but produce experiences impalpable in registers of pathology and therapy. Even as a disseminated commodity, it creates mechanical hugs incorporating two-way modifications and intimacy apart from health care treatment programs.

It is my claim that, in this respect, this human-nonhuman collective exceeds many of Grandin's explanations of the machine's functions. I argue that it equally surpasses the above mentioned Latourian framework. Grandin's alliance with the machine can admittedly be comprehended as a distinct human-nonhuman association, also identified by Latour as "person-machine interface" (2000: II). Moreover, it might vividly manifest a hybrid of a human and a "technical object" as depicted by him: "[o]ne generally finds oneself in the realm ... of what is called the 'body corporate' or the 'artificial person'” (I999: I92). The artifacts that Latour chooses as examples, however, display an instrumentality that subverts his own argument. Be it a handgun or a speed bump (cf. ibid.: I76-I80, I86-I87), they are typically of practical or, in any case, purposive value. They make humans reach - howsoever ferocious - goals in manners that curiously threaten to re-erect the very subject-object dichotomy that Latour wants to dispose of. Due to its non-instrumental and non-targeted traits, the Grandin-machine interface - or rather, the Grandin-machine assemblage - may be a better illustration of a Latourian conception of a new type of social. This assemblage essentially questions the duty of "delegation," which he equivocally attributes to nonhuman actants. According to 
him, "[a]n object stands in for an actor" (ibid.: 189). A speed bump then works as a "sleeping policeman"' (ibid.: 186). This contradicts his compelling designation of nonhuman actants as "mediators," as opposed to "intermediaries": Whereas intermediaries are surrogates which merely relay messages that can also be formulated elsewhere, mediators have a profound influence on these messages; they can shape or sabotage them. They are "endowed with the capacity to translate what they transport, to redefine it, redeploy it, and also to betray it" (Latour 1993: 8I). Unlike the cases Latour cites, Grandin's squeeze machine perfectly exemplifies these mediators. It does not deputize or symbolize interpersonal occurrences. It is not an intermediary, carrying out acts of human communication in nonhuman guise, like a speed bump does. Instead, it makes relations - of a not purely human kind. In other words, even though Grandin sketches it at times as a "delegate" for people hugging her, the special qualities of its embrace transcend such assignment. The hug machine might be a thing that is liberated from "standing in." Perhaps this is where the magic of the magical device lies?

\section{Towards a More-Than-Human Sociality}

Grandin's representations of the machine and, first and foremost, her practices around it, re-shaped the knowledge about autism and the discourse on it, its research and therapy. ${ }^{19}$ They were used to trace the condition back to special ways of sensory processing, to overpowering or insufficient stimulations. ${ }^{20}$ Maria Almanza ascribes "embodied knowledge" (2016: I73) to the machine: "Grandin's account of her sensory experience is intimately linked to the squeeze machine." It "gives testimony to Grandin's unique sensory life" (ibid.: I66).

Furthermore, the Grandin-machine assemblage inherently revaluates criteria that have traditionally been regarded as core symptoms and deficits defining autism. I have already pointed out that the assemblage permits and enables "aloneness," long classified as the main deviation exhibited by autistics. It also accommodates an affinity for objects that was originally treated as a pathological sign of autism, too. In his first studies on "autistic disturbances of affective contact," child psychiatrist Leo Kanner not only identified aloneness and insistence on sameness as characteristics of the children he soon diagnosed with "early infantile autism" (1943: 249; 1944). He also emphasized that his young patients treated people "as if 
they were objects" (Kanner 1944: 212), meaning with indifference. At the same time, they would strangely connect with real objects like artifacts or toys, handling them "with care and even affection" (1944: 2I2). This assumption implies that their attachments to items resembled the ones children without "infantile autism" typically had toward people - and it reinforces a longstanding hierarchy of subjects and objects, rigidly distinguishing the sorts of relationships one should naturally have to each of them. For Kanner, his patients' "good relation to objects" (1943: 246, original emphasis) thus manifested their deviance. He also associated it with what he designated as autism's main symptom. Objects are preferred over people, because they "never threaten to interfere with the child's aloneness" (ibid.). By devoting himself to objects, the autist "has a gratifying sense of undisputed power and control," as Kanner concluded (I944: 216).

Grandin's conjunction with the squeeze machine is an intimate bondage with a lifeless device, more intimate than the devotion to objects that Kanner once scandalized. In the beginning, she too is unsettled about this, since it was criticized, most importantly, by her mother. Grandin cites a letter from her stating that "[o]bjects cannot speak to you or hug you. Objects are only something made out of imagination and energy and raw materials" (I996: I05; original emphasis). However, Grandin's persistent habit of using the machine profoundly questions this presumption: It lets the machine communicate with her and embrace her. It appreciates the force that stems from the "imagination, energy and raw materials," of which the object - or more precisely, the thing - is made. Likewise, and as I have demonstrated, Kanner's idea regarding the autist's "undisputed power and control" over artifacts is scrutinized by the power and control of Grandin's apparatus. I have also shown that her alliance with the machine confounds any clear order of subjects and objects.

Her maintaining a close relation to a machine evokes as much as it reassesses another stereotypical notion of autism. To date, it has been linked with a problematic kind of mechanization: Either the parenting of autistic children, the rapport people with autism have with others, their conduct, or even just autistics themselves have frequently been portrayed as mechanical or technical, as an impoverished or downright subhuman existence (cf., e.g., Asperger I944: 93, III; Kanner 1945: 25; I949: 422; Bettelheim 1959, 1967). ${ }^{21}$ In her narrative of her life and especially in writing about the squeeze machine, Grandin, by contrast, positively marks her attraction to mechanical gadgets and technology as a gift (Grandin/Scariano I996: 38). What has for many decades been understood as aberrance, she turns into a potential and passion. Besides, in her entanglement with the apparatus, "mechanical" does not 
metaphorically refer to a behavior deprived of interpersonal "warmth," but it is a fitting term for the very functionality at hand: an effective mechanization of touch.

The Grandin-machine assemblage brings about, or in Latourian vocabulary, "articulates" (Latour 2004: 86; I999: I87), a specific kind of contact. It is physical, mental, and social - i.e., happening among actants. But it is always based on tactile encounters and thus matches the genuine connotation of the word contact. Hugging here is no more and no less than a sensory experience between oneself and one's surroundings. It has no currency in the business of interhuman exchange, no representational duties. There are reasons to interpret this type of contact as an autistic being in touch.

This is not meant to impose yet another definition of autism from an allistic, i.e. non-autistic, viewpoint. ${ }^{22}$ Firstly, however, this approach is feasible, according to Grandin's own understanding of the condition. Since she conceives of autism as an augmented responsivity to sensations, the equally magnified and regulated sensory occurrences within the machine can indeed be grasped in terms of a particular relationality to one's environment. This relationality is non-discursive, non-intentional, and beyond hermeneutic logics of symbols or denotations. Instead, it is driven by dynamics of immersion, penetrability, and perceptual intensities. It is "an invention that allows for the autist's creative relation to other people, objects, and animals" (Almanza 2016: I69).

Secondly, the "embodied knowledge" of Grandin's machine and this very relationality resonate with recent utterances made by other people with autism. They deny being disconnected from the outside world or non-communicative, instead emphasizing how strongly they interact - given that interaction is fathomed differently. Autism advocate Mel Baggs, for instance, did not use verbal language. She reported, however, being in continuous dialogue with the spaces around her, including things and materials like water, which, for Baggs, clearly had agency. ${ }^{23}$ Her communication with them was non-symbolic.

$[\mathrm{M}] \mathrm{y}$ language is not about designing words or even visual symbols for people to interpret. It is about being in a constant conversation with every aspect of my environment. Reacting physically to all parts of my surroundings. ... Far from being purposeless, the way that I move is an ongoing response to what is around me. (Baggs 2007) ${ }^{24}$

Philosopher Erin Manning contends that for Mel Baggs " $[\mathrm{t}]$ here is nothing but relation" (2012: IO, original emphasis). Manning speculates that autists are the sole adults able to perceive this comprehensive relationality - "affective attunement" (ibid.: II) - 
with our ambience, since most humans purportedly lose it while growing up. Those "affective attunements" vary significantly from the "affective contact" Kanner posits between people. ${ }^{25}$ Manning refers to an idea of affect held to be an "event" that "concerns the movements of the body" and "is not subjective in the sense of belonging to a subject to which the body belongs" (Massumi 2015: I05). ${ }^{26}$ Furthermore, it is not bound to volition (cf. Manning 20I6: 19-20).

For Melanie Yergeau, "involuntarity" is a crucial element of an autistic rhetoric that she asserts. She also calls it a "sensorimotor rhetoric" (20I8: 56). For her, it flips rhetorical traditions grounded on intentionality or symbolism. In autistic rhetoric, intention might emanate from body parts and meaning from "[p]erceptual signification" (ibid.: 55) rather than from any structure of representation. It is a rhetoric that "tics, ... stims" and "averts eye contact" (ibid.: 3I). Grandin's hug machine can be viewed as a manifestation of such rhetorics. It articulates stims; it also affords a concurrency and dispersion of agency and non-agency in both involved parties that are at the center of Yergeau's conception of an autistic rhetoric. This rhetoric - as does the Grandin-machine assemblage - rejects criteria of purpose, causation, or finality. It features processuality and non-discursiveness. Moreover, an "irreducible relationality" appertains to it which is "forged with and between things, fields, spaces, air particles, moments, motions" (ibid.: 72). Here Yergeau seems to aptly capture the above-mentioned relationality entailed by Grandin's machine. Such "irreducible relationality," similarly outlined by Baggs and Manning, goes along with what Yergeau describes as a distinctive sociality in autistic rhetorics. It is "without a you or a me" (ibid.: 34, original emphasis), and "more than human" (ibid.: 7I).

The Grandin-machine assemblage indeed generates and expresses a sociality that does not prioritize any human affiliation but fosters one with a thing that eventually becomes Grandin's steady and intimate companion. ${ }^{27}$ More indirectly, it also connects her to animals. Its first scheme was born after she had put herself figuratively and then literally into a cow's position. It emerged from the kinship with animals which she accredits to herself and many autistic people, a kinship she claims to repeatedly perceive when in the machine. As an animal scientist and professional designer of livestock facilities, she developed chutes for cattle, based on her experiential insight from the use of her device. In turn, her observations of chutes at feedlots helped her technically improve her own apparatus.

Grandin also devised a large part of the slaughterhouses in the US, enforcing supposedly humane standards by applying her knowledge of the soothing impact of tactile pressure. She relates how she once constructed a cattle chute for kosher 
slaughter. She herself directed the mechanism to calm a cow before and while it was being killed: "[T]he parts of the apparatus that held the animal felt as if they were an continuation of my own body, similar to the phantom limb effect" (Grandin 2006: 25). This chute constitutes a mediator. It allows Grandin to hug an ani$\mathrm{mal}^{28}$ or the animal, the chute, and Grandin to form an animal-nonhuman-human association. ${ }^{29}$ According to Gary Wolfe, this scene attests to "trans-species affinity" (Wolfe 2010: 120). Grandin here "crosses not only the lines of species difference, but also of the organic and inorganic, the biological and mechanical" (ibid.: II7). Wolfe considers her "disability" the very qualifier for the ability to traverse those divides. ${ }^{30}$ So does Grandin herself. In Animals in Translation, she writes: "Autism is a kind of way station on the road from animals to humans, which puts autistic people like me in a perfect position to translate 'animal talk' into English" (Grandin/Johnson 2006: 6-7). For her self-image, her familiarity with animals has been as crucial as her familiarity with mechanical things. To Grandin, autism is where species meet. ${ }^{31}$ In any case, the assemblages made possible by Grandin's hug machine or her aforementioned cattle chute transcend the typical regime of species which distinguishes between humans, animals and objects. These assemblages indeed enable "variable ontologies" (Latour 1993: 85) - but again, in a more radical and consistent manner than Latour envisions. They enhance wider-reaching affiliations and impel morethan-human affective ecologies.

Many recent remarks by those who are experts on autism through experience lastingly reframe ideas about it. Instead of considering it a disorder defined by deficiencies, they value it as a legitimate and rich way of being. Instead of locating it within a barred and walled domain, they view it as a key that opens extensive worlds. Temple Grandin was the first public autistic specialist on autism. During the past 30 years, her presence and her statements have been crucial and influential for debates on the condition. Numerous texts of hers, however, contribute to its ongoing pathologizing. They uphold the ideal of integrating people with autism into neurotypical cultures, assigning those cultures normalcy and normativity.

One could, however, arguably conceive of her hug machine as an autism advocate avant la lettre. This would make another act of the machine discernible: In its association with Grandin it brings forth an autistic being in touch. It thereby modifies assumptions about what it means to be autistic and about what it means to be in touch. The magical device can make us rethink the human, and it might truly reassemble the social. 


\section{Notes}

1

This might explain the divergent information Grandin gives on her diagnostic history (cf. 1996: 11; 2006: 33). In this regard and concerning Grandin's supposed early signs of autism, her account also deviates from her mother's (cf. Cutler 2004: 6-7, 25, 30).

\section{2}

A year before, in 1985, David Eastham's book Understand: Fifty Memowriter Poems was released, which is, according to Melanie Yergeau, "[a]rguably the first published autie-biography" (2018: 21). However, it largely went unnoticed.

\section{3}

This is based on a curious juxtaposition: Large parts of her book contain general, matter-offact paragraphs using selected evidence from science, which are only loosely connected to the descriptions of her personal experiences.

\section{4}

In seminal writings on infantile autism, it was presented as an outcome of a non-loving attitude of parents, especially mothers, towards their offspring (cf., e.g., Kanner 1949). Because of the alleged traumatizing lack of emotional warmth and care, the autistic child would retreat into her barred-off universe, rejecting dynamics of interpersonal relations altogether. See Bettelheim (1967) and footnote 11 of this article.

\section{5}

She believes this threshold of "tactile defensiveness" affects many autistic people (cf., e.g., Grandin/Scariano 1996: 36-37).

\section{6}

A chapter titled "The Magical Device" is dedicated to the machine and positioned in the very middle of her book. However, the apparatus is mentioned in nearly every chapter.

\section{7}

For the machine's technical details see, e.g., Grandin/Scariano (1996: 182-184).

\section{8}

For a lucid differentiation of a "processual, bodily affect" and a "subjective, representable emotion," see Bösel (2018: 19).

\section{9}

Inadequate or plainly absent emotion in autistic patients has been a ubiquitous topic in the psy disciplines, especially in psychoanalytically inclined studies (cf., e.g., Kanner 1943; Bettelheim 1959, 1967)

10

See Foucault (1988) and Rose (1996).

11

The diary entry by the younger Grandin cited in this paragraph imparts a singular significance to the motherly hug, while the older Grandin, consistent with most of her statements about hugs, describes them as a bodily stimulation defined by technical parameters, yielding measurable physical effects. In some sequences of her book, however, her ambiguous notions of "hugging" become apparent. She explains her longing for being touched through a want of embraces, namely from a nanny who had rejected the concept of physical tenderness. Grandin ascribes symbolic quality to hugs as expressions of "affection" - another term she uses equivocally: "Since the governess ... never hugged or touched my sister or me, I craved tender touching. I ached to be loved - hugged" (Grandin/Scariano 1996: 36). This curiously preserves an all too familiar idea of autism, linking it to the fault of a tender and warm familial milieu (cf. Kanner 1944, 1949; Bettelheim 1959, 1967). Grandin replaces the emotionally negligent mother - a recurring figure in the discursive history of autism - with the governess, thus indirectly reanimating the "cold mother," without blaming her own mother. 
12

For the history of the pathologizing of self-stimulation and its association with masturbation, see Yergeau (2018: 201-202). The early criticism of Grandin's hug machine can also be explained by a not yet established discourse on self-stimulation. Much less did there exist a positive understanding of it.

\section{3}

See most prominently the seminal work Kanner (1943).

\section{4}

I will address the discrimination between human and animal and its subversion by Grandin's use of the machine in the next chapter.

\section{5}

This is mostly a nominal distinction, however, since human and nonhuman parties, for Latour, act in similar ways.

\section{6}

In this phrase, he applies "actants" as a word for both human and nonhuman parties.

\section{7}

Here I am referring to Latour's mention of "swapping properties among inert, animal, symbolic, concrete, and human materials" (1999: 190).

\section{8}

See Therafin Corporation, http://www.therafin. com/squeezemachine.htm, accessed July 5, 2019

\section{9}

Especially after the publication of Emergence in 1986, the machine influenced scientific studies on autism and methods of treatment; its clinical value was progressively acknowledged (cf., e.g., Krauss 1987). Even before the release of her autobiography, Grandin also began to author and co-author articles in the area of autism research (cf. Grandin 1984; 1992; Edelson et al. 1999). Applying deep pressure has been increasingly approved of as treatment for autistic patients (cf. Bestbier/Williams 2017). Accordingly, the use of squeezing devices inspired by Grandin's apparatus has become a suggested means (cf. Duvall 2017).

\section{0}

The most recent definition of autism in the Diagnostic and Statistical Manual of Mental Disorders (DSM) lists "hyper- or hyporeactivity to sensory input" (American Psychiatric Association 2013) as a symptom relevant for its diagnoses.

For recent "[s] ensorimotor approaches" (Yergeau 2018: 195) to autism see, e.g., Tavassoli et al. (2019); Neil et al. (2016); Donnellan et al. (2013); Savarese (2013); Green et al. (2012); Pellicano/ Burr (2012); Mottron et al. (2006); Jones et al. (2003); O’Neill/Jones (1997).

\section{1}

This notion is still strongly tangible in psychologist Simon Baron-Cohen's influential ascription of a genetically inherited "technical mind" to people with autism (cf. Baron-Cohen 2012). For the ever-present discursive linkage of autists with apparatuses, preferably robots, in science and popular culture see Göhlsdorf (2019a: 292f; 2019b). Amit Pinchevski and John Durham Peters also stress the continuous interleaving of autism and the technical world (cf. 2016: 2514).

\section{2}

Rather, I consider it one potential autistic way of being in touch, that is prevalent and a matter of wider discussion among people with autism. Still, for an allistic author, there is a precariously fine line between, on the one hand, reflecting autism founded on statements and practices of those identifying themselves as autistic and, on the other hand, putting the label "autism" onto a phenomenon one does not experience oneself, thus repeating a violent gesture that has dominated autism's history.

\section{3}

Pinchevski and Peters therefore locate Baggs "on the cutting edge of new materialism, thing theories, and what Walter Benjamin (1973) called "empathy with inorganic things'" (Pinchevski/ 
Peters 2016: 2520). For them, Baggs and other autistics "may be the pioneers of object-oriented ontologies" (ibid.). Baggs, who died in April 2020, was non-binary and preferred to be referred to by the pronouns "sie" and "hir."

\section{4}

This text forms part of a YouTube video authored and produced by Baggs. The words are uttered by a computerized voice and legible in subtitles from minute 3:32 through 4:05. https://www. youtube.com/watch?v=JnylMIh/2jc

\section{5}

Manning, however, borrows this term from Daniel Stern, who focused on "affect attunement" between mothers and their not yet verbal children (cf. Stern 1998: 138-161).

\section{6}

See also Bernd Bösel's account on the "eventology" (2018: 19-20) of affect, building on Brian Massumi's theory.

\section{7}

Although I deem Oliver Sacks's much-noticed portrait of Temple Grandin, including her hug machine, highly problematic, he offers a credible description of how the device accompanies her in everyday life (cf. Sacks 1995: 262-265).

\section{8}

This setting recalls the chute that Grandin's aunt operated with Grandin inside of it, allowing the aunt to give her niece a hug that could not be realized without the chute.

\section{9}

This particular cattle chute also serves as a prosthesis for Grandin. Grandin's hug machine has been analyzed as a "prosthetic extension of the self" (Almanza 2016: 162, original emphasis) as well. However, Almanza's depiction of the machine as "a prosthetic, non-linguistic means for Grandin to communicate her needs to others" (ibid.: 196) is questionable, because it again subordinates the apparatus to primarily interpersonal processes.
30

For Wolfe, Grandin's self-apprehension within a "register of the technical and mechanical" (2010: 131) and as someone who shares ways of visual and tactile perception with animals alludes to an idea of an "ahuman" (ibid.: 112) inspiring a productive convergence of post-human thought and disability studies. By "[l] earning from Temple Grandin" (ibid.: 127), Wolfe declines to base affinity across species on "subjectivity as agency" (ibid.: 138, original emphasis) but, instead, on "vulnerability and passivity" or - in Derrida's words - on "'non-power at the heart of power" (ibid.: 141). Even though Wolfe does not make such a reference, his conception of "non-power" can also be applied to the non-agency, or rather semi-agency, that is effectuated by the hug machine.

\section{1}

It would be fruitful to also examine Grandin's hug machine with the help of Donna Haraway's work on, e.g., the interspecies "subject- and object-shaping dance of encounters" (2008: 4). It is not possible within the scope of this article. For good reasons, however, the Grandin-hug machine assemblage can be understood as a cyborg in the way illustrated by Haraway, too. Furthermore, it would be productive to draw on her thoughts on the autonomy of machines and boundary confusions (cf. Haraway 2016). 


\section{Bibliography}

Almanza, Maria (2016): “Temple Grandin's Squeeze Machine as Prosthesis." In: Journal of Modern Literature 39/4, pp. 162-175

American Psychiatric Association (2013): Diagnostic and Statistical Manual of Mental Disorders (5th ed.), Washington DC, https://doi.org/10.1176/ appi.books.9780890425596 (F84.0), accessed August 19, 2019

Asperger, Hans (1944): "Die 'Autistischen Psychopathen' im Kindesalter." In: Archiv für Psychiatrie und Nervenkrankheiten 117, pp. 76-136. Baggs, Mel (2007): In My Language, https:// www.youtube.com/watch?v=JnylMlhl2jc, accessed August 19, 2019.

Baron-Cohen, Simon (2012): "Autism and the Technical Mind." In: Scientific American 307/5, pp. 72-75.

Bestbier, Lana/Williams, Tim I. (2017): "The Immediate Effects of Deep Pressure on Young People with Autism and Severe Intellectual Difficulties: Demonstrating Individual Differences." In: Hindawi. Occupational Therapy International, https://doi.org/10.1155/2017/7534972, accessed August 19, 2019.

Bettelheim, Bruno (1959): "Joey: A 'Mechanical Boy.". In: Scientific American 200/3, pp. 116-127. Bettelheim, Bruno (1967): The Empty Fortress: Infantile Autism and the Birth of Self, New York: The Free Press.

Bösel, Bernd (2018): "Affect Disposition(ing): A Genealogical Approach to the Organization and Regulation of Emotions." In: Media and Communication 6/3, pp. 15-21.

Cutler, Eustacia (2004): A Thorn in My Pocket: Temple Grandin's Mother Tells the Family Story, Arlington TX: Future Horizons.

Donellan, Anne M./Hill, David A./Leary, Martha R. (2013): "Rethinking autism: implications of sensory and movement differences for understanding and support." In: Frontiers in Integrative Neuroscience 6/124, n. pag., https://doi.org/10.3389/fn int.2012.00124, accessed August 19, 2019.
Duvall, Julia Claire (2017): Bear Hug: The Design and Development of an Active Deep Touch Pressure Garment for Sensory Processing Disorder, master's thesis, University of Minnesota, https:// conservancy.umn.edu/handle/11299/191299, accessed August 19, 2019.

Eastham, David E. (1985): Understand: fifty memowriter poems, ed. by Anne Grice, Ottawa: Oliver Pate.

Edelson, S. M./Edelson, M. G./Kerr, D. C./Grandin, T. (1999): "Behavioural Physiological Effects of Deep Pressure on Children with Autism: A Pilot Study Evaluating the Efficacy of Grandin's Hug Machine." In: The American Journal of Occupational Therapy 53/2, pp. 145-152.

Foucault, Michel (1988): "Technologies of the Self." In: Luther H., Martin/Gutman, Huck/Hutton, Patrick H. (eds.): Technologies of the Self. A Seminar with Michel Foucault, London: Tavistock, pp. 16-49.

Göhlsdorf, Novina (2019a): "Autismus: Diagnose der Gegenwart." In: Kinder- und JugendlichenPsychotherapie. Zeitschrift für Psychoanalyse und Tiefenpsychologie 50/182, pp. 277-303.

Göhlsdorf, Novina (2019b): "Der seelenlose Cyborg. Wenn Philosophen hassen." In: Frankfurter Allgemeine Sonntagszeitung, August 11, p. 34

https://www.faz.net/aktuell/feuilleton/debatten/wiephilosoph-michel-onfray-greta-thunberg-pathologisiert-16325690.html, accessed August 19, 2019

Grandin, Temple (1984): "My Experiences as an Autistic Child and Review of Selected Literature." In: Journal of Orthomolecular Psychiatry 13/3, pp. 144-174

Grandin, Temple (1992): "Calming Effects of Deep Touch Pressure in Patients with Autistic Disorder, College Students, and Animals." In: Journal of Child and Adolescent Psychopharmacology 2/1, pp. 63-72

Grandin, Temple (2006 [1995]): Thinking in Pictures and Other Reports from My Life with Autism, London: Bloomsbury.

Grandin, Temple/Johnson, Catherine (2006 [2005]): Animals in Translation: The Woman Who Thinks Like a Cow, London: Bloomsbury. 
Grandin, Temple/Johnson, Catherine (2010): Animals Make Us Humans: Creating the Best Life for Animals, New York: Harcourt.

Grandin, Temple/Scariano, Margaret M. (1996 [1986]): Emergence. Labeled Autistic, New York: Grand Central.

Green, Shulamite A./Ben-Sasson, Ayelet/Soto, Timothy W./Carter, Alice S. (2012): "Anxiety and Sensory Over-Responsivity in Toddlers with Autism Spectrum Disorders: Bidirectional Effects Across Time." In: Journal of Autism and Developmental Disorders 42/6, pp. 1112-1119.

Haraway, Donna (2016): "A Cyborg Manifesto: Science, Technology, and Socialist-Feminism." In: Haraway, Donna: Manifestly Haraway, Minneapolis/ London: University of Minnesota Press, pp. 3-90. Haraway, Donna (2008): When Species Meet, Minneapolis/London: University of Minnesota Press. Jacobson, Pearl (2012): "Profiles in Science for Science Librarians: Temple Grandin." In: Science E Technology Libraries 31/4, pp. 343-360.

Jones, Robert S. P./Quigney, Ciara/Huws, Jaci C. (2003): "First-hand accounts of sensory perceptual experiences in autism: a qualitative analysis." In: Journal of Intellectual \& Developmental Disability 28/2, pp. 112-121.

Kanner, Leo (1943): "Autistic Disturbances of Affective Contact." In: Nervous Child 2, pp. 217-250. Kanner, Leo (1944): "Early Infantile Autism." In: Journal of Pediatrics 25, pp. 211-217.

Kanner, Leo (1945): "Child Rearing by the Book." In: The American Mercury 60/253, pp. 23-28.

Kanner, Leo (1949): "Problems of Nosology and Psychodynamics of Early Infantile Autism." In: American Journal of Orthopsychiatry 19/3, pp. 416-426. Kapp, Steven K./Steward, Robyn/Crane, Laura/Elliott, Daisy/Elphick, Chris/Pellicano, Elizabeth/Russell, Ginny (2019): “'People Should Be Allowed to Do What They Like': Autistic Adults' Views and Experiences of Stimming." In: Autism, February 28, https:// doi.org/10.1177/1362361319829628, accessed August 19, 2019.

Krauss, Kevin (1987): “The Effects of Deep Pressure Touch on Anxiety." In: The American Journal of Occupational Therapy 41/6, pp. 366-373.
Latour, Bruno (1993): We Have Never Been Modern, transl. by Catherine Porter, Hertfordshire: Harvester Wheatsheaf.

Latour, Bruno (1999): Pandora's Hope. Essays on the Reality of Science Studies, Cambridge MA/ London: Harvard University Press.

Latour, Bruno (2000): "The Berlin Key or How to Do Words with Things." In: Graves-Brown, Paul (ed.): Matter, Materiality and Modern Culture, New York: Routledge, pp. 10-21.

Latour, Bruno (2004): Politics of Nature. How to Bring the Sciences into Democracy, transl. by Catherine Porter, Cambridge, MA/London: Harvard University Press.

Latour, Bruno (2005): Reassembling the Social: An Introduction to Actor-Network-Theory, Oxford: Oxford University Press.

Manning, Erin (2012): Always More Than One: Individuation's Dance, Durham/London: Duke University Press.

Manning, Erin (2016): The minor gesture, Durham/ London: Duke University Press.

Massumi, Brian (2015): The Power at the End of the Economy, Durham: Duke University Press.

Mottron, Laurent/Dawson, Michelle/Soulières, Isabelle/Hubert, Benedicte/Burack, Jake (2006): "Enhanced Perceptual Functioning in Autism:

An Update and Eight Principles of Autistic Perception." In: Journal of Autism and Developmental Disorder 36/1, pp. 27-43.

Murray, Stuart (2008): Representing Autism: Culture, Narrative, Fascination, Liverpool: Liverpool University Press.

Neil, Louise/Olsson, Nora Choque/Pellicano, Elizabeth (2016): "The Relationship between Intolerance of Uncertainty, Sensory Sensitivities, and Anxiety in Autistic and Typically Developing Children." In: Journal of Autism and Developmental Disorder 46/6, pp. 1962-1973.

O’Neill, Meena/Jones, Robert S. P. (1997): "Sensory-Perceptual Abnormalities in Autism: A Case for More Research." In: Journal of Autism and Developmental Disorder 27/3, pp. 283-293.

Pellicano, Elizabeth/Burr, David (2012): "When the world becomes 'too real': A Bayesian explanation 
of autistic perception." In: Trends in Cognitive Sciences 16/10, pp. 504-510.

Pinchevski, Amit/Peters, John Durham (2016) "Autism and new media: Disability between technology and society." In: new media \& society 18/ 11, pp. 2507-2523

Rose, Nikolas (1996): Inventing Our Selves. Psychology, Power, and Personhood, Cambridge: Cambridge University Press.

Sacks, Oliver (1995): An Anthropologist on Mars.

Seven Paradoxical Tales, New York: Vintage Books.

Savarese, Ralph J. (2013): "Moving the field: the sensorimotor perspective on autism (Commentary on 'Rethinking autism: implications of sensory and motor differences,' an article by Anne Donnellan, David Hill, and Martha Leary)." In: Frontiers in Integrative Neuroscience 7/6, n. pag., https://doi.org/10.3389/fnint.2013.00006, accessed August 19, 2019

Stern, Daniel N. (1998 [1985]): The Interpersonal World of an Infant: A View from Psychoanalysis and Developmental Psychology, London: Karnac Books.

Tavassoli, Teresa/Brandes-Aitken, Anne/Chu, Robyn/Porter, Lisa/Schoen, Sarah/Miller, Lucy Jane/Gerdes, Molly Rae/Owen, Julia/Mukherjee, Pratik/Marco, Elysa J. (2019): "Sensory over-responsivity: parent report, direct assessment measures, and neural architecture." In: Molecular Autism 10/4, https://doi.org/10.1186/s13229-0190255-7, accessed August 19, 2019.

Wolfe, Gary (2010): What is Posthumanism? Minneapolis: University of Minnesota Press.

Yergeau, Melanie (2018): Authoring autism: On rhetoric and neurological queerness, Durham/ London: Duke University Press. 
